\title{
Nuclear Magnetic Resonance Characterizes Metabolic Differences in Cymbopogon Schoenanthus Subsp. Proximus Embryogenic and Organogenic Calli and their Regenerated Shoots
}

\author{
Asmaa Abdelsalam \\ Helwan University Faculty of Science \\ Kamal Chowdhury \\ Claflin University \\ Arezue Boroujerdi ( $\sim$ aboroujerdi@claflin.edu ) \\ Claflin University \\ Ahmed El-Bakry \\ Helwan University Faculty of Science
}

\section{Research Article}

Keywords: In vitro regeneration, Medicinal plants, Metabolomics, Multivariate analysis, NMR spectroscopy.

Posted Date: June 29th, 2021

DOI: https://doi.org/10.21203/rs.3.rs-541378/v1

License: (c) (1) This work is licensed under a Creative Commons Attribution 4.0 International License. Read Full License

Version of Record: A version of this preprint was published at Plant Cell, Tissue and Organ Culture (PCTOC) on December 1st, 2021. See the published version at https://doi.org/10.1007/s11240-02102202-3. 


\section{Abstract}

Cymbopogon schoenanthus subsp. proximus is a threatened wild grass well known for its folk medicine uses and possesses a broad spectrum of pharmacological properties. In this study, the metabolite differences between embryogenic and organogenic calli have been characterized. Changes in the metabolome of somatic embryogenesis and organogenesis have been studied by comparing the metabolites of morphogenic calli with their respective regenerated shoots. Based on ${ }^{1} \mathrm{H}$ and HSQC NMR data of the polar extracts, a total of 51 metabolites have been identified. Statistical analyses were performed to visualize the pattern of metabolites distribution among the studied groups. Glycolate present in organogenic calli, but not in organogenic calli. Some metabolites like glucose-6-phosphate, 4aminobutyrate and arginine showed elevated concentrations in embryogenic calli than organogenic calli. While sucrose and myo-inositol up regulated in organogenic calli than embryogenic calli. Metabolites that marked embryogenic shoots from embryogenic calli have been described. Quantitatively, embryogenic shoots showed higher concentrations of sucrose, some amino acids, and trigonelline compared with embryogenic calli. In contrast, glucose, fructose, and arginine accumulated in embryogenic calli more than in embryogenic shoots. Likewise, metabolites characterized organogenic shoots from organogenic calli have been identified. Sucrose, several amino acids and trigonelline were detected in higher concentrations in organogenic shoots than in organogenic calli while monosaccharides and arginine accumulated in organogenic calli than in organogenic shoots. This study represents a first step towards understanding the metabolic activity of calli and shoots regenerated through different morphogenetic pathways.

\section{Introduction}

Cymbopogonschoenanthus subsp. proximusisa perennial grass that grows wild in southern areas of the Egyptian desert.The plant is used in traditional medicine for treatment diabetes, inflammation, parasitic infection, and renal spasms(Boulos 1983). Previous studies have reported the antioxidant and antimicrobial activities of the plant extract (Selim 2011; Hashim et al. 2016). Crude extract of the plant is used inProximol ${ }^{\circledR} \mathrm{drug}$ production which is prescribed for ureteric stones, excess uric acid and urate crystals in urine and urinary tract infection cases.Previous phytochemical investigations havereportedthat the plantextract is rich inmono-as well assesquiterpene metabolites(El Tahir and Abdel-Kader 2008).

In vitro propagation of plants can be achieved through different techniques (Kumar and Reddy 2011). Somatic embryogenesis and organogenesis are two different techniques for in vitro regeneration of plants (Phillips 2004). In somatic embryogenesis, somatic cells differentiate into bipolar structures (somatic embryo) that later lead to a whole plant. Somatic embryogenesis is a suitable approach through which in vitro plant models can be obtained, and thus allow many genetic and physiological investigative studies to be easily conducted (Méndez-Hernández et al. 2019). In contrast, the shoot organogenesis gives rise to only unipolar structures (shoot); mainly used for clonal propagation (Hicks 1994). Somatic embryogenesis and organogenesis are the most used micropropagation methods in genus Cymbopogon (Bhattacharya et al. 2009; Dey et al. 2010) In our previous studies, different methods for 
micropropagation of $C$. schoenanthus subsp. proximushave been successfully achieved, and included somatic embryogenesis, direct organogenesis, and de novo organogenesis (El-Bakry and Abdelsalam 2012, Abdelsalam et al. 2017a, 2018).

Differencesbetweenthe embryogenic and non-embryogenic calli of many plants have been previously reported, e.g. sugarcane, carnation and Oryza sativa plants(Nieves et al. 2003; Karami and Ostad-Ahmadi 2008; Vega et al. 2009). Both tissue systems have shown differentmorphological, anatomical, and histological characters, as well as phytochemicalcomposition. Though, the metabolomic analysis of the embryogenic and non-embryogenic calli of some plants using NMR spectroscopy has been discussed before (Parrilla et al.2018), no previous studies have addressed the difference between the embryogenic and organogenic calli at the metabolomic level.

Hence, the present study was carried out toanalyze and comparethe metabolome ofthe embryogenicand organogeniccalliof the medicinal important herb, $C$. schoenanthus subsp.proximususingNMR spectroscopy. Furthermore, the changesin the metabolic profiles that take place during the somatic embryogenesis and the organogenesis processes were discussed, principally, through comparing the metabolites of the embryogenic and organogeniccalli with their respective regenerated shoots.

\section{Materials And Methods}

\section{Plant material and seed sterilization}

Mature inflorescences of $C$. schoenanthus were collected in April 2015 from the botanical garden of Aswan University, Egypt and were kept in dark at $25^{\circ} \mathrm{C}$.Mature seeds wereseparated, rinsed with tap water for $15 \mathrm{~min}$ and soaked in distilled water for $5 \mathrm{~min}$. The seed surfacewas sterilized using $95 \%$ ethanol for 1 min, followed by $20 \%$ Clorox solution $(5.25 \% \mathrm{NaOCl})$ for $20 \mathrm{~min}$ under stirring. Under aseptic conditions, Clorox solution was removed, and seeds were rinsed 3 times in sterile double distilled $\mathrm{H}_{2} \mathrm{O}$.

\section{Embryogenic callus induction and plant regeneration via somatic embryogenesis}

Sterile seeds were cultured onMurashige and Skoog media (1962) with B5 vitamins (Gamborg et al. 1968)(MSB5) containing 3\% sucrose, supplemented with $4 \mathrm{mg} / \mathrm{L} 2$, 4-Dichlorophenoxy acetic acid (2, 4 D) and $0.5 \mathrm{mg} / \mathrm{L}$ 6-Benzyl adenine (BA) for 4 weeks.Embryogeniccalli(EC)in six replications were collected, frozen in liquid nitrogen and stored at $-80^{\circ} \mathrm{C}$.Somatic embryo maturation and germinationwere performed by transferring the embryogenic calli to MSB5 medium with one fourththe concentration of growth regulators. Regenerated shootswere transferred to a medium containing $0.2 \mathrm{mg} / \mathrm{L}$ BAfor further shoot elongation. Finally, somatic embryo-derived shoots (ES) were harvested after 12 weeks from initial seed culture. Subculture was carried out every four weeks.

\section{Organogenic callus induction and plant regeneration via de novo organogenesis}


To induce organogeniccalli(OC), surface-sterilized seeds were cultured on MSB5containing $3 \%$ sucrose and supplemented with $0.5 \mathrm{mg} / \mathrm{L}$ BAand $4 \mathrm{mg} / \mathrm{L}$ 1-Naphthaleneacetic acid (NAA). Ten Petri dishes were cultured with 5 seeds each. After 4 weeks, organogeniccallifrom nine dishes were individually collectedin liquid nitrogen after removing excess medium. To regenerate organogenic shoots (OS), organogeniccalli were sub-cultured ontomagenta boxes containing $50 \mathrm{~mL}$ of the same medium composition and growth regulator concentrations. Regenerated shootswere harvested after eight weeks ofinitial seed culture (Abdelsalam et al. 2018).

For all tissue culture experiments, the $\mathrm{pH}$ of the tissue culture medium was adjusted to5.7 before adding phytagel, $2 \mathrm{~g} / \mathrm{L}$, sterilized at $120^{\circ} \mathrm{C}$ and $1 \mathrm{kgcm}^{-2}$ pressure for $20 \mathrm{~min}$. Thecultureswere maintained at $25^{\circ} \mathrm{C}$ under cool white fluorescent light (3000 lux) for $8 \mathrm{~h}$ light photoperiod for calli and $16 \mathrm{~h}$ photoperiod for shoots.

\section{Sample preparation and metabolite extraction}

From six to nine replicates from each callus and shoot type were collected carefully, immersed directly in liquid nitrogen, and then stored at $-80^{\circ} \mathrm{C}$ for at least $4 \mathrm{~h}$ before lyophilization. Dry tissues were ground to powder and homogenized. Twenty $\mathrm{mg}$ from each replicate was used for metabolite extraction. The metabolites were extracted according toKim et al.(2010) using a constant volumetric ratio of 2:2:1 from methanol: chloroform: water based on dry mass and water loss ratio (Bligh and Dyer 1959; Wu et al. 2008). The polar layer was removed from the extract and dried under vacuum for $24 \mathrm{~h}$.

\section{NMR sample preparation and data collection}

Each dry samplewas re-suspendedina constant volume $(620 \mu \mathrm{L})$ of NMR buffer $(1 \mathrm{mM}$ TMSP, $100 \mathrm{mM}$ sodium phosphate buffer and $0.1 \%$ sodium azide, in 99.9 atom \% $\mathrm{D}_{2} \mathrm{O}$ ).NMR spectroscopic data (1D and 2D) were collected at $25^{\circ} \mathrm{C}$ on a $700 \mathrm{MHz}$ BrukerAvance ${ }^{\mathrm{TM}}$ III spectrometer. Predefined NMR experimental parameters as well as data processing were followed as previously reported (Abdelsalam et al.2017b).

\section{NMR data analysis}

Metabolites were identified from the polar fraction of the calli and shoots by comparing the ${ }^{1} \mathrm{H}$ data with the Chenomx NMR Suite library of compounds (Chenomx Inc., Edmonton, Alberta, Canada). Confirmation of Chenomx assignments wereachievedby comparing ${ }^{1} \mathrm{H}-{ }^{13} \mathrm{C}$ HSQC data with ${ }^{1} \mathrm{H}^{-13} \mathrm{C}$ HSQC data available online in MMCD (Madison Metabolomics Consortium Database) (http://mmcd.nmrfam.wisc.edu/)and with those reported in the literature. One $D$ and 2D NMR spectrawere labeled using Mnova software.

Statistical analyses (Principal componentsanalysis (PCA), fold change analysis, cluster analyses) were carried out using MetaboAnalyst4.0 (MetaboAnalyst4.0 - a comprehensive server for metabolomics data analysis) based on bucket table's created by AMIX softwarewith $95 \%$ confidence intervals (Xia et al. 2012). The spectral region was $0.5-10.0 \mathrm{ppm}$ with $0.01 \mathrm{ppm}$ bucket widths and advance bucketing; water regions $(4.7-4.8 \mathrm{ppm})$ were excluded from the spectra. The spectral bins were normalized to total 
intensity.Cluster analyses were carried out using Ward's linkage as a clustering algorithm andEuclidean distance as a similarity measuring.

\section{Results And Discussion}

As a part of our ongoing research on the medicinal herb $C$. schoenanthus subsp. proximus, herein, we report the metabolic variation between embryogenic and organogenic calli. We also identified metabolome variation in somatic embryogenesis and organogenesis by comparing the metabolic profiles of the EC and OC with their respective regenerated shoots, ES and OS, respectively.

EC can be readily distinguished from OC through morphological features. Embryogenic calli (EC) were dark yellow color, granular, compact, and friable in texture (Fig. 1A). On the other hand, OC were transparent, glossy, less granular, and non-friable (Fig. 1B). Shoots regenerated from somatic embryogenesis were harvested after 12 weeks from initial seed culture. Morphologically, they had a pale green color, 2-3 cm leaf length and leaf width 1-3 mm (Fig. 1C). Organogenic shoots (8 weeks old) were dark green in color with $3-5 \mathrm{~cm}$ leaf length and $0.5 \mathrm{~cm}$ leaf width (Fig. 1D).

Metabolic profiling of the polar extract from calli and shoots using NMR spectroscopy led to the characterization of 51 compounds in total (Table 1). The identified compounds belonged to various classes of chemicals e.g., amino acids, sugars, and alkaloids. The molecular formulas, chemical shifts and coupling constants of all metabolites are listed in table 1 in the supplementary data.

The metabolites variation between different morphogenic calli and between morphogenic calli and their corresponding regenerated shoots were accomplished through the unsupervised PCA, fold change as well as cluster analyses.

\section{Metabolites difference between EC and OC}

A total of 41 compounds were identified in EC and OC polar extract. Qualitatively all metabolites were identified in both types of callus except for glycolate detected in OC.

Score plots, constructed using 2D and 3D pairwise PCA analysis, illustrated a clear separation between EC and OC samples (Fig. 2A, B) due to variation in the metabolites. The metabolites responsible for this separation were identified using heat map correlation and fold change analyses (Table 2 \& 3, Fig. $2 \mathrm{C}$ \& $5 \mathrm{~A})$. The data showed that some metabolites recorded elevated concentrations in EC than OC. These were identified as carbohydrates as, glucose-6-phosphate (G-6-P); amino acids as 4-aminobutyrate, arginine, asparagine, betaine, and proline. On the other hand, $\mathrm{OC}$ accumulated more sucrose and myoinositol than EC.

Sucrose is a non-reducing disaccharide that cleaved by the action of invertase into the building monohexosides. Early stages of somatic embryogenesis were shown to have a boosted activity of invertase (Iraqi and Tremblay 2001; Konradova et al. 2002) which might explain the recorded increase of G-6-P in EC than OC. Glucose can be utilized by the plant after phosphorylation to G-6-P by hexokinase 
enzymes (Granot et al. 2013). Glucose-6-P has many functions in the plant. It can convert to UDPglucose which is vital for polysaccharides and cell wall biosynthesis; also essential in glycosylation reactions of different compounds for example terpenoids and flavonoids (Kleczkowski et al. 2010). Moreover, Dyson et al. 2014 reported that the G-6-P is essential in controlling the transition process from the heterotrophic status to photosynthetic status in plants; also it is important for zygotic embryo germination in Arabidopsis.

The amino acids, 4-aminobutyrate, betaine and proline were reported to accumulate in response to stress conditions (Waditee et al. 2002; Signorelli et al. 2015; Xiong et al. 2021). This may explain their existence in EC in a higher concentration. The EC are known to develop under stress conditions resulting from the use of 2, 4-D on the culture medium. This growth regulator is known as a stress factor during somatic embryogenesis (Shariatpanahi et al. 2006). Moreover, the transition from somatic cell to somatic embryos was found to activate the expression of stress-associated genes (Jin et al. 2014; Salvo et al. 2014). The accumulation of the amino acids proline and arginine in EC may arise from the essential role of these metabolites in somatic embryogenesis process. Proline has an important function in somatic embryos maturation in conifer and strawberry plants (Feirer 1995; Gerdakaneh and Mozafari 2011). Arginine is a precursor of polyamines in plant through arginine decarboxylase enzyme. Polyamines are necessary in somatic embryogenesis and their decrease leads to reduction in the embryogenesis process (Bertoldi et al. 2004; Minocha et al. 2004). In other studies, high concentrations of arginine and asparagine had been reported in embryogenic callus of Boesenbergia rotunda, Silybum marianum and Brachypodium distachyon compared to non-embryogenic calli ( $\mathrm{Ng}$ et al. 2016; Khan et al. 2015; Mamedes-Rodrigues et al. 2018). Arginine has been reported to accumulate in date palm under salinity stress (Al Kharusi et al. 2020)

\section{Metabolites difference between EC and ES}

PCA analysis of EC and ES showed that the samples from calli were grouped together and completely separated from the samples of shoots in $2 \mathrm{D}$ and $3 \mathrm{D}$ score plots (Fig. 3A, B).

As indicated by heat map correlation and fold change analysis (Table $2 \& 3$, Fig. 3C \& 5B), ES showed higher intensities of sucrose, several amino acids (asparagine, betaine, glutamate, phenyl alanine, proline, and pyroglutamate) and trigonelline alkaloid. On the other hand, the monosaccharides (glucose and fructose) and amino acids i.e. arginine were up regulated in EC.

Higher concentration of hexoses along with lower concentration of sucrose in EC compared to ES could refer to the important role of the simple sugars like glucose and fructose in cell proliferation and differentiation processes needed for transition from EC to plantlet stage. These metabolites variations during embryogenesis have been reported in several preceding studies (Borisjuk et al. 1998; Hill et al. 2003; Hudec et al. 2016). Carbohydrates are considered as a signal for gene expression during plant growth, developmental and floral transition (Weber et al. 1997; Eveland and Jackson 2012). 
The accumulation of glutamate in shoots to a higher level than in the calli may be due to that the enzymes responsible for their biosynthesis (glutamate synthase) are present in different isoforms in plant leaves (Hirel and Lea 2002; Forde and Lea 2007). Also, glutamate is a precursor of chlorophyll biosynthesis in plants (Reinbothe and Reinbothe 1996; Yaronskaya et al. 2006). Moreover, CangahualaInocente et al. (2014) suggested the decrease in amino acid level in early stage of somatic embryogenesis is due to their necessity in cell differentiation to complete development process.

Proline also showed a higher intensity in ES which may be attributed to the stress resulting from the longterm culturing conditions. Its role in cell protection during long-term stress has been reported by Kishor and Sreenivasulu (2014).

The accumulation of arginine in EC may be because it is a precursor of many compounds as urea, nitric oxide, and polyamines. These metabolites have a regulatory role in cell development and early seedling germination (Feirer 1995; King and Gifford 1997).

\section{Metabolites Differences between OC and OS}

Organogenic calli and shoots were clearly distinguished in 2D and 3D scores plots studied samples (Fig. $4 A, B)$.

Based on heat map correlation and fold change analysis (Table 2 \& 3, Fig. 4C \& 5C. Organogenic shoots were characterized by higher concentrations of sucrose and amino acids as alanine, asparagine, leucine, and threonine, while monosaccharides (glucose, glucose-6-phosphate, and fructose) and the amino acid arginine were accumulated in OC. Trigonelline up regulated in shoots to a higher level than in calli.

Sucrose accumulation in OS is because it is an autotrophic tissue, able to produce sucrose during photosynthesis. We suggest that most of the amino acids observed to have been up regulated in shoots because these are a photosynthetic green cell. Hildebrandt et al. (2015) reported that the accumulation of amino acids in growing photosynthetic tissues is due to support protein synthesis. Also, some of these amino acids have some roles which are restricted in chloroplast and green tissue, for example asparagine was found to play role in photorespiration process in Pea leaves (Ta et al. 1986). Furthermore, amino acids alanine, aspartate, glutamate, threonine, and glycine can be synthesis in leaves during photosynthesis process from intermediates biosynthesis of carbon reduction pathway (Bassham al. 1964; Kirk and Leech 1972). Palma et al. (2010) reported high concentrations of amino acids asparagine, glutamine and valine in shoot differentiated callus of Vanilla planifolia plant when compared to undifferentiated callus.

In the present study, trigonelline concentration in OS was higher than its concentration in OC. In our previous work (Abdelsalam et al. 2017b) we reported the presence of trigonelline in wild plants and in in vitro regenerated shoots. Here, trigonelline has been also recognized in both types of calli. Trigonelline is a pyridine alkaloid synthesized through the methylation of nicotinic acid and known to possess 
anticancer activity (Chen and Wood, 2004). This alkaloid was reported to accumulate in leaves of many plants including Coffea arabica (Ashihara 2006).

\section{Metabolites differences between morphogenic calli and de novo regenerated shoots}

To study the correlations between shoots and calli, multivariate analysis has been carried out. The unsupervised PCA analysis showed that EC, OC, ES and OS are separated into four groups in both 2D and 3D scores plots (Fig. 6 A, B). Dendrogram cluster analysis between shoots and calli (Fig. 6C) showed two main clusters, shoots from embryogenesis and organogenesis were grouped on one cluster, while EC and $\mathrm{OC}$ were grouped in the other cluster. The metabolic profiles of calli tissues and de novo regenerated shoots showed that nine compounds were detected in shoots but not in calli tissues. Six metabolites were identified in only one shoot type (Table 1).

Only ES were characterized by the presence of serine and lactate metabolites. The most important biosynthetic pathway of serine is the glycolate pathway which is restricted to autotrophic tissue (Bauwe et al. 2010; Häusler et al. 2014), which may explain the absence of serine from calli tissues. Also, the essential role of serine under stress conditions (Ho and Saito 2001) and embryo development (Yamaoka et al. 2011, Ros et al. 2014) may explain the presence of this amino acid in ES. The presence of lactate has been correlated to hypoxic stress in Arabidopsis (Dolferus et al. 2008).

Tyrosine was detected only in OS. It is an aromatic amino acid and was reported to control organogenesis in tobacco callus (Skoog 1971). We suggest that tyrosine was not detected in either EC or $\mathrm{OC}$ because the high activity of cell proliferation and growth during this stage to produce organs. This condition was reported to decrease the biosynthesis of tyrosine and increase biosynthesis of phenyl alanine from their common precursor, chorismate (Schenck and Maeda 2018). Also, in ES tyrosine may be broken down because of the stress culture conditions. Tyrosine degradation under stress conditions was documented by Frelin et al. (2017). Tyrosine is a precursor of a number of metabolites which possess many physiological functions in plants is and used as human drug (Schenckand Maeda 2018).

Shoots regenerated from somatic embryogenesis and organogenesis were characterized by the presence of lysine. Lysine is an essential amino acid with high nutritional value (Fornazier et al. 2003). The presence of lysine in shoots rather than calli may be because many of the enzymes that participate in their biosynthesis are known to be in plastid (Bryan 1990).

Both organogenic callus and shoots showed the presence of glycolate which was absent from EC and ES. Glycolate is metabolized during photorespiration process. It can be converted to various metabolites e.g. glycine, serine and glycerate (Tolbert 1979). The effect of 2, 4-D on glycolate metabolism through activation of glycolate oxidase has been reported in pea leaves (McCarthy-suarez 2011). Our data may suggest that the presence of 2, 4-D in the culture medium of somatic embryogenesis may increase the metabolism of glycolate to glycine in EC and to serine in ES.

\section{Conclusion}


Morphogenic calli whether embryogenic or organogenic,were metabolically distinct from the green autotrophic shoots, both qualitativelyand quantitatively. When compared to shoots, calli had higher concentrations of hexosesas glucose, fructose, glucose-6-P, and the amino acid arginine. Regenerated shoots showeda number of key metabolites which were found characteristic to the autotrophic metabolically active plant tissue, i.e. sucrose, alanine, asparagine and trigonelline. Embryogenic callus was clearly differentfrom organogenic callus; the former accumulated higher concentrations of aminoacidssuch as4-aminobutyrate, betaine and proline.On the other hand, organogenic callus has uniquely producedglycolate. Such metabolites variations may be attributed to the difference in culture spans and growth regulators used for induction in each case. Embryogenicshoots obtained from calli induced on 2, 4-D and regenerated after a relatively prolonged culture span showed marker metabolitesas serine and lactate.Organogenic shoots obtained from calli induced using NAA and regenerated aftershorter culture spanwere characterized by the presence of histamine, homoserine and tyrosine.

Our findings suggest that shoots regenerated throughde novo organogenesis to be more physiologically developed and metabolically active than their somatic embryogenesis counterparts. The present study is considered as a first step towards understanding the metabolic activity of shoots regenerated invitrothrough different morphogenetic pathways. Also, metabolites that characterize different types of morphogenetic calli were identified as an expression of their metabolism underculture conditions, involving stress conditions, during their growth and development.

\section{Abbreviations}

EC: Embryogenic calli

OC: organogenic calli

ES: Embryogenic shoots

OS: organogenic shoots

NMR: Nuclear Magnetic Resonance

BA: 6-Benzyladenine

NAA: Naphthaleneacetic acid

2,4-D: 2,4 Dichlorophenoxy acetic acid

MS-B5:Murashige and Skoog 1962; Gamborg et al. 1968

\section{Declarations}

\section{Funding}


This work was funded by the Culture Affairs and Missions Sector, Ministry of Higher Education in Egypt, SC-INBRE (2 P20 GM103499), NSF HBCU-UP (HRD-1332516) and NSF MRI (DBI-1429353).

\section{Conflicts of interest}

Asmaa Abdelsalam, Kamal Chowdhury, Arezue Boroujerdi and Ahmed El-Bakry declare that they have no conflict of interest.

\section{Ethics approval and consent to participate}

Not applicable

\section{Consent $f$ or publication}

Not applicable

\section{Availability of data and materials}

All data generated or analyzed during this study are included in this published article.

\section{Authors' contributions}

All authors contributed to the study conception and design. Material preparation, data collection and analysis were performed by Asmaa Abdelsalam. The first draft of the manuscript was written by Asmaa Abdelsalam. Kamal Chowdhury and Arezue Boroujerdi and Ahmed El-Bakry edited the manuscript. All authors approved the final manuscript.

\section{References}

1. Abdel-Salam AM, Chowdhury K and El-Bakry AA (2017a) Micropropagation through in vitro tillering from seed cultures of the medicinal Plant Cymbopogon schoenanthus subsp. proximus. Asian J. Applied Sciences 5: 31-40.

2. Abdelsalam A, Mahran E, Chowdhury K, Boroujerdi A, El-Bakry A (2017b) NMR-based metabolomic analysis of wild, greenhouse, and in vitro regenerated shoots of Cymbopogon schoenanthus subsp. proximus with GC-MS assessment of proximadiol. Physiol Mol Biol Plants 1-15.

3. Abdel-Salam AM, Chowdhury K, El-Bakry AA (2018) Efficient adventitious morphogenesis from in vitro cultures of the medicinal plant Cymbopogon schoenanthus. Plant Tissue Cult Biotechnol 25:5162.

4. Al Kharusi L, Jana GA, Patankar HV, Yaish MW (2020) Comparative Metabolic Profiling of Two Contrasting Date Palm Genotypes Under Salinity. Plant Molecular Biology Reporter. 2020: 19:1-3.

5. Ashihara H (2006) Metabolism of alkaloids in coffee plants. Braz. J. Plant Physiol 18:1-8. 
6. Bassham JA (1964) Kinetic studies of the photosynthetic carbon ${ }^{1,2,3}$ reduction. Annu Rev Plant Physiol 15:101-120.

7. Bauwe H, Hagemann M, Fernie AR (2010) Photorespiration: players, partners and origin. Trends Plant Sci 15: 330-336.

8. Bertoldi D, Tassoni A, Martinelli L, Bagn N (2004) Polyamines and somatic embryogenesis in two Vitis vinifera cultivars. Physiol Plant 20: 657-666.

9. Bhattacharya S, Bandopadhtay TK, Ghosh PD (2009) Somatic embryogenesis in Cymbopogon pendulus and evaluation of clonal fidelity of regenerates using ISSR marker. Sci Hortic 123:505-513.

10. Bligh EG, Dyer WJ (1959) A rapid method of total lipid extraction and purification. Can J Biochem Physiol 37:911-917.

11. Borisjuk L, Walenta S, Weber H, Mueller-Klieser W, Wobus U (1998) High resolution his to graphical mapping of glucose concentrations in developing cotyledons of Vicia faba in relation to mitotic activity and storage processes: glucose as a possible developmental trigger Plant J 15:583-591.

12. Boulos L (1983) Medicinal plants of North Africa. Reference Publication Inc., Michigan.

13. Bryan JK (1990) Advances in the biochemistry of amino acid biosynthesis. In: Miflin BJ, Lea PJ (eds) The Biochemistry of Plants, Vol. 16. New York: Academic Press, pp. 161-196.

14. Cangahuala-Inocente GC, Silveira V, Caprestano CA, Floh EIS, Guerra MP (2014) Dynamics of physiological and biochemical changes during somatic embryogenesis of Acca sellowiana. In Vitro Cell Dev Biol- Plant 50: 166

15. Chen X, Wood AJ (2004) Purification and characterization of S-adenosyl-L-methionine nicotinic acid$\mathrm{N}$-methyl transferase from leaves of Glycine max. Biol Plant 48: 531-535.

16. Dey T, Bhattacharya S, Ghosh PD (2010) Somatic embryogenesis from rhizome explants of Cymbopogon winterianus. Biol Plant 54:325-328.

17. Dolferus R, Wolansky M, Carroll R, Miyashita Y, Ismond K, Good A (2008) Functional analysis of lactate dehydrogenase during hypoxic stress in Arabidopsis. Funct Plant Biol 35:131-140.

18. Dyson BC, Webster RE, Johnson GN (2014) GPT2: a glucose 6-phosphate/phosphate translocator with a novel role in the regulation of sugar signaling during seedling development. Ann Bot 113: 643652.

19. El Tahir KEH, Abdel-Kader M (2008) Chemical and pharmacological study of Cymbopogon proximus volatile oil. Rese J Med Plant 2:53-60.

20. El-Bakry AA, Abelsalam AM (2012) Regeneration from embryogenic callus and suspension cultures of the wild medicinal plant Cymbopogon schoenanthus. Afr J Biotechnol 11:10098-10107.

21. Eveland AL, Jackson DP (2012) Sugars, signalling, and plant development. J Exp Bot 63:3367-3377

22. Feirer RP (1995) The biochemistry of conifer embryo development: amino acids, polyamines and storage proteins. In: Jain SM, Gupta PK \& Newton RJ (eds) Somatic Embryogenesis in Woody Plants Vol. 1 (. Kluwer Academic Publishers, Dordrecht, The Netherlands, pp. 317-336 
23. Forde BG, Lea PJ (2007) Glutamate in plants: metabolism, regulation and signalling. J Exp Biol 58: 2339-2358.

24. Fornazier RF, Azevedo RA, Ferreira RR, Varisi VA (2003) Lysine catabolism: flow, metabolic role and regulation. Braz J Plant Physiol 15:9-18.

25. Frelin O, Dervinis C, Wegrzyn JL, Davis JM, Hanson AD (2017) Drought stress in Pinus taeda L. induces coordinated transcript accumulation of genes involved in the homogentisate pathway. Tree Genet Genomes 13- 27.

26. Gamborg OL, Miller RA, Ojima K (1968) Nutrient requirements of suspension culture of soybean root cells. Exp Cell Res 50:151-158.

27. Gerdakaneh M, Mozafari A, sioseh-mardah A, Sarabi B (2011) Effects of different amino acids on somatic embryogenesis of strawberry (Fragaria 3 ananassa Duch.) Acta Physiol Plant 33:1847-1852.

28. Granot D, David-Schwartz R, Kelly G (2013) Hexose kinases and their role in sugar-sensing and plant development. Front. Plant Sci. 4:1-17.

29. Hashim GM, Almasaudi SB, Azhar E, Al Jaouni SK, Harakeh S (2016) Biological activity of Cymbopogon schoenanthus essential oil. Saudi J Biol Sci 1-7.

30. Häusler RE, Ludewig F, Krueger S (2014) Amino acids - A life between metabolism and signaling. Plant Sci 229: 225-237.

31. Hicks GS (1994) Shoot Induction and organogenesis in vitro: a developmental perspective. In Vitro Cell. Dev Biol 30:10-15.

32. Hildebrandt TM, Nesi NA, Araújo WL, Braun HP (2015) Amino acid catabolism in plants. Mol. Plant 8:1563-1579.

33. Hill LM, Morley-Smith E R, Rawsthorne S (2003) Metabolism of sugar in the endosperm of developing seeds of oil seed rape. Plant Physiol 131: 228-236.

34. Hirel B, Lea PJ (2002) The biochemistry, molecular biology, and genetic manipulation of primary ammonium assimilation. In: Foyer $\mathrm{CH}$, Noctor $\mathrm{G}$ (eds) Photosynthetic nitrogen assimilation and associated carbon and respiratory metabolism. Kluwer, London, pp 71-92.

35. Ho CL, Saito K (2001) Molecular biology of the plastidic phosphorylated serine biosynthetic pathway in Arabidopsis thaliana. Amino Acids 20:243-259.

36. Hudec L, Konrádová H, Hašková A, Lipavská H (2016) Norway spruce embryogenesis: changes in carbohydrate profile, structural development and response to polyethylene glycol. Tree Physiol 36: 548-561.

37. Iraqi D, Tremblay FM (2001) Analysis of carbohydrate metabolism enzymes and cellular contents of sugars and proteins during spruce somatic embryogenesis suggests a regulatory role of exogenous sucrose in embryo development. J Exp Biol 52:2301-2311.

38. Jin F, Hu L, Yuan D, Jiao Xu J, Gao W, He L, Yang X, Zhang X (2014) Comparative transcriptome analysis between somatic embryos (SEs) and zygotic embryos in cotton: evidence for stress response functions in SE development. Plant Biotechnol Journal 12: 161-173. 
39. KaramiO, Ostad-Ahmadi P (2008) Morphology, histology and protein patterns in embryogenic and non embryogenic callus of Carnation. Floriculture Ornamental Biotech 2:12-13.

40. Khan M, Abbasi B, Ali H, Ali M, Adil M, Hussain I (2014) Temporal variations in metabolite profiles at different growth phases during somatic embryogenesis of Silybum marianum L. Plant Cell Tiss Organ Cult 1-13.

41. Kim HK, Choi YH, Verpoorte R (2010) NMR-based metabolomics analysis of plants. Nat Protoc 5:536-549.

42. King JE, Gifford DJ (1997) Amino acid utilization in seeds of loblolly pine during germination and early seedling growth (I. Arginine and Arginase activity). Plant Physiol 113:1125-1135.

43. Kirk PR, Leech RM (1972) Amino acid biosynthesis by isolated chloroplasts during photosynthesis. Plant Physiol 50:228-234.

44. Kishor PBK, Sreenivasulu N (2014) Is proline accumulation per se correlated with stress tolerance or is proline homeostasis a more critical issue?. Plant Cell Environ 37: 300-311.

45. Kleczkowski LA, Kunz S, Wilczynska M (2010) Mechanisms of UDP-glucose synthesis in plants. Crit Rev Plant Sci 29:191-203.

46. Konrádová H, Lipavská H, Albrechtová J, Vreugdenhil D (2002) Sucrose metabolism during somatic and zygotic embryogenesis in Norway spruce: Content of soluble saccharides and localization of key enzyme activities. J. Plant Physiol 159: 387-396.

47. kumar N, Reddy MP (2011) In vitro Plant Propagation: A Review. Journal of Forest Science 27:61-72.

48. Mahmud I, Thapaliya M, Boroujerdi A, Chowdhury K (2014) NMR based metabolomics study of the biochemical relationship between sugarcane callus tissues and their respective nutrient culture media. Anal Bioanal Chem 406:5997-6005.

49. Mamedes-Rodrigues TC, Batista DS, Vieira NM, Matos EM, Fernandes D, Nunes-Nesi A, Cruz CD, Viccini LF, FNogueira FTS, Otoni WC (2018) Regenerative potential, metabolic profile, and genetic stability of Brachypodium distachyon embryogenic calli as affected by successive subcultures. Protoplasma 255: 655-667.

50. McCarthy-Suárez I, Gómez M, del Río LA, Palma JM (2011) Role of peroxisomes in the oxidative injury induced by the auxin herbicide 2,4-D in leaves of pea plants. Biol Plant 55:485-492.

51. Méndez-Hernández HA, Ledezma-Rodríguez M, Avilez-Montalvo RN, Juárez-Gómez YL, Skeete $A$, Avilez-Montalvo J, De-la-Peña C, Loyola-Vargas VM (2019) Signaling overview of plant somatic embryogenesis. Front. Plant Sci. 10:77.

52. Minocha R, Minocha SC, Long S (2004) Polyamines and their biosynthetic enzymes during somatic embryo development in red spruce (Picea rubens Sarg). In Vitro Cell Dev Biol-Plant 40: 572.

53. Murashige T, Skoog F (1962) A revised medium for rapid growth and bioassay with tobacco tissue culture. Plant Physiol 15:473-497.

54. Nieves N, Segura-Nieto M, Blanco MA, Sánchez M, González A, González JL, Castillo R (2003) Biochemical characterization of embryogenic and non-Embryogenic calluses of sugarcane. In Vitro 
Cell Dev Biol- Plant. 39: 343-345.

55. Palama TL, Menard P, Fock I, Choi YH, Bourdon E, Govinden- Soulange J, Bahut M, Payet B, Verpoorte R, Kodja H (2010) Shoot differentiation from protocorm callus cultures of Vanilla planifolia (Orchidaceae): proteomic and metabolic responses at early stage. BMC Plant Biol 10:82-90.

56. Parrilla J, Gaillard C, Verbeke J, Maucourt M, Aleksandrov RA, Thibault F, Fleurat-Lessard P, Gibon Y, Rolin D, Atanassova R (2018) Comparative metabolomics and glycolysis enzyme profiling of embryogenic and non-embryogenic grape cells. FEBS Open Bio. 17:784-798.

57. Phillips GC (2004) In vitro morphogenesis in plants-recent advances. In Vitro Cell.Dev.Biol.-Plant 40: 342.

58. Reinbothe S, Reinbothe C (1996) Regulation of Chlorophyll Biosynthesis in Angiosperms. Plant physiol 111: 1-7.

59. Ros R, oz-Bertomeu JM, Krueger S (2014) Serine in plants: biosynthesis, metabolism, and functions. Trends Plant Sci 19:564-569.

60. Salvo SAGD, Hirsch CN, Buell CR, Kaeppler SM, Kaeppler HF (2014) Whole transcriptome profiling of maize during early somatic embryogenesis reveals altered expression of stress factors and embryogenesis-related genes. PLOS ONE 9 (10).

61. Schenck CA, Maeda HA (2018) Tyrosine biosynthesis, metabolism, and catabolism in plants. Phytochemistry 149:82-102.

62. Selim SA (2011) Chemical composition, antioxidant and antimicrobial activity of the essential oil and methanol extract of the Egyptian lemongrass Cymbopogon proximus Stapf. Grasas Aceites 62:55-61.

63. Shariatpanahi ME, Bal U, Heberle-Bors E, Alisher Touraev A (2006) Stresses applied for the reprogramming of plant microspores towards in vitro embryogenesis. Physiol Plant 127: 519-534.

64. Signorelli S, Dans PD, Coitiño EL, Borsani O, Monza J (2015) Connecting proline and Y-amino-butyric acid in stressed plants through non-enzymatic reactions. PLOS ONE 10 (3): e0115349.

65. Skoog F (1971) Aspects of growth factor interactions in morphogenesis of tobacco tissue culture. Colloq. Int. CRNS. 193: 115-135.

66. Ta TC, Joy KW (1986) Metabolism of some amino acids in relation to the photo respiratory nitrogen cycle of pea leaves. Planta 169: 117-122.

67. Tolbert NE (1979) Glycolate metabolism by higher plants and algae. In: Gibbs M., Latzko E. (eds) Photosynthesis II. Encyclopedia of Plant Physiology (New Series), vol 6. Springer, Berlin, Heidelberg.

68. Vega R, Vasquez N, Espinoza AM, Gatica AM, Melara MV (2009) Histology of somatic embryogenesis in rice (Oryza sativa cv. 5272). Revista de Biologia Tropical, 57: 141-150.

69. Waditee R, Hibino T, Tanaka Y, et al (2002) Functional characterization of betaine/proline transporters in betaine-accumulating mangrove. J Biol Chem 277: 18373-18382.

70. Weber L, Borisjuk L, Wobus U (1997) Sugar import and metabolism during seed development. Trends Plant Sci. 2:169-174. 
71. Wu H, Southam AD, Hines A, Viant MR (2008) High-throughput tissue extraction protocol for NMRand MS-based metabolomics. Anal Biochem 372:204-212.

72. Xia J, Mandal R, Sinelnikov IV, Broadhurst D, Wishart DS (2012) MetaboAnalyst 2.0-a comprehensive server for metabolomics data analysis. Nucleic Acids Res 40:127-133.

73. Xiong Y, Qu Y, Han H, Chen F, Li L, Tang H, Che D, Zhang X (2021) Unraveling Physiological and Metabolomic Responses Involved in Phlox subulata L. Tolerance to Drought Stress. Plant Molecular Biology Reporter, 39:98-111.

74. Yamaoka Y, Yu Y, Mizoi J, Fujiki Y, Saito K, Nishijima M, Lee Y, Nishida I (2011) PHOSPHATIDYLSERINE SYNTHASE1 is required for microspore development in Arabidopsis thaliana. Plant J 67: 648-661.

75. Yaronskaya E, Vershilovskaya I, Poers, Alawady AE, Averina N, Grimm B (2006) Cytokinin effects on tetrapyrrole biosynthesis and photosynthetic activity in barley seedlings. Planta 224: 700-709.

\section{Tables}


Table 1

List of metabolites identified by ${ }^{1} \mathrm{H}$ and ${ }^{1} \mathrm{H}-{ }^{13} \mathrm{C}$ HSQC NMR analyses of polar extracts $(E C=$ embryogenic callus; $\mathrm{OC}=$ organogenic callus; $\mathrm{ES}=$ embryogenic shoots; OS = organogenic shoots). The check mark $(\sqrt{ })$ indicates the presence of the compound in the corresponding type of tissue

\begin{tabular}{|c|c|c|c|c|c|}
\hline & Compound Name & EC & $\mathrm{OC}$ & ES & OS \\
\hline 1 & 2-Hydroxylsobutyrate & - & - & - & $\sqrt{ }$ \\
\hline 2 & 4-Aminobutyrate & $\sqrt{ }$ & $\sqrt{ }$ & $\sqrt{ }$ & $\sqrt{ }$ \\
\hline 3 & 4-Hydroxy benzoate & - & - & $\sqrt{ }$ & $\sqrt{ }$ \\
\hline 4 & 4-Pyridoxate & - & - & $\sqrt{ }$ & $\sqrt{ }$ \\
\hline 5 & Acetate & $\sqrt{ }$ & $\sqrt{ }$ & $\sqrt{ }$ & $\sqrt{ }$ \\
\hline 6 & Alanine & $\sqrt{ }$ & $\sqrt{ }$ & $\sqrt{ }$ & $\sqrt{ }$ \\
\hline 7 & Asparagine & $\sqrt{ }$ & $\sqrt{ }$ & $\sqrt{ }$ & $\sqrt{ }$ \\
\hline 8 & Aspartate & $\sqrt{ }$ & $\sqrt{ }$ & $\sqrt{ }$ & $\sqrt{ }$ \\
\hline 9 & Betaine & $\sqrt{ }$ & $\sqrt{ }$ & $\sqrt{ }$ & $\sqrt{ }$ \\
\hline 10 & Choline & $\sqrt{ }$ & $\sqrt{ }$ & $\sqrt{ }$ & $\sqrt{ }$ \\
\hline 11 & Citrate & $\sqrt{ }$ & $\sqrt{ }$ & $\sqrt{ }$ & $\sqrt{ }$ \\
\hline 12 & cis-Aconitate & $\sqrt{ }$ & $\sqrt{ }$ & $\sqrt{ }$ & - \\
\hline 13 & Dimethylamine & $\sqrt{ }$ & $\sqrt{ }$ & $\sqrt{ }$ & $\sqrt{ }$ \\
\hline 14 & Ethanolamine & $\sqrt{ }$ & $\sqrt{ }$ & $\sqrt{ }$ & $\sqrt{ }$ \\
\hline 15 & Formate & $\sqrt{ }$ & $\sqrt{ }$ & $\sqrt{ }$ & $\sqrt{ }$ \\
\hline 16 & Fructose & $\sqrt{ }$ & $\sqrt{ }$ & $\sqrt{ }$ & $\sqrt{ }$ \\
\hline 17 & Fumarate & $\sqrt{ }$ & $\sqrt{ }$ & $\sqrt{ }$ & $\sqrt{ }$ \\
\hline 18 & Gallate & - & - & $\sqrt{ }$ & $\sqrt{ }$ \\
\hline 19 & Galactarate & $\sqrt{ }$ & $\sqrt{ }$ & $\sqrt{ }$ & $\sqrt{ }$ \\
\hline 20 & Glucose & $\sqrt{ }$ & $\sqrt{ }$ & $\sqrt{ }$ & $\sqrt{ }$ \\
\hline 21 & Glucose-1-Phosphate & $\sqrt{ }$ & $\sqrt{ }$ & $\sqrt{ }$ & $\sqrt{ }$ \\
\hline 22 & Glucose - 6-P & $\sqrt{ }$ & $\sqrt{ }$ & $\sqrt{ }$ & $\sqrt{ }$ \\
\hline
\end{tabular}




\begin{tabular}{|c|c|c|c|c|c|}
\hline & Compound Name & EC & $\mathrm{OC}$ & ES & OS \\
\hline 23 & Glutamine & $\sqrt{ }$ & $\sqrt{ }$ & $\sqrt{ }$ & $\sqrt{ }$ \\
\hline 24 & Glutamate & $\sqrt{ }$ & $\sqrt{ }$ & $\sqrt{ }$ & $\sqrt{ }$ \\
\hline 25 & Glutarate & $\sqrt{ }$ & $\sqrt{ }$ & $\sqrt{ }$ & $\sqrt{ }$ \\
\hline 26 & Glycine & $\sqrt{ }$ & $\sqrt{ }$ & $\sqrt{ }$ & $\sqrt{ }$ \\
\hline 27 & Glycolate & - & $\sqrt{ }$ & - & $\sqrt{ }$ \\
\hline 28 & Histamine & - & - & - & $\sqrt{ }$ \\
\hline 29 & Homoserine & - & - & - & $\sqrt{ }$ \\
\hline 30 & Isobutyrate & $\sqrt{ }$ & $\sqrt{ }$ & $\sqrt{ }$ & $\sqrt{ }$ \\
\hline 31 & Isoleucine & $\sqrt{ }$ & $\sqrt{ }$ & $\sqrt{ }$ & $\sqrt{ }$ \\
\hline 32 & Isovalerate & $\sqrt{ }$ & $\sqrt{ }$ & $\sqrt{ }$ & $\sqrt{ }$ \\
\hline 33 & Lactate & - & - & $\sqrt{ }$ & - \\
\hline 34 & Leucine & $\sqrt{ }$ & $\sqrt{ }$ & $\sqrt{ }$ & $\sqrt{ }$ \\
\hline 35 & Lysine & - & - & $\sqrt{ }$ & $\sqrt{ }$ \\
\hline 36 & Malate & $\sqrt{ }$ & $\sqrt{ }$ & $\sqrt{ }$ & $\sqrt{ }$ \\
\hline 37 & Malonate & $\sqrt{ }$ & $\sqrt{ }$ & $\sqrt{ }$ & - \\
\hline 38 & Myo-inositol & $\sqrt{ }$ & $\sqrt{ }$ & $\sqrt{ }$ & $\sqrt{ }$ \\
\hline 39 & Phenylalanine & $\sqrt{ }$ & $\sqrt{ }$ & $\sqrt{ }$ & $\sqrt{ }$ \\
\hline 40 & Proline & $\sqrt{ }$ & $\sqrt{ }$ & $\sqrt{ }$ & $\sqrt{ }$ \\
\hline 41 & Pyroglutamate & $\sqrt{ }$ & $\sqrt{ }$ & $\sqrt{ }$ & $\sqrt{ }$ \\
\hline 42 & Pyruvate & $\sqrt{ }$ & $\sqrt{ }$ & $\sqrt{ }$ & $\sqrt{ }$ \\
\hline 43 & Serine & - & - & $\sqrt{ }$ & - \\
\hline 44 & Succinate & $\sqrt{ }$ & $\sqrt{ }$ & $\sqrt{ }$ & $\sqrt{ }$ \\
\hline 45 & Sucrose & $\sqrt{ }$ & $\sqrt{ }$ & $\sqrt{ }$ & $\sqrt{ }$ \\
\hline 46 & Threonine & $\sqrt{ }$ & $\sqrt{ }$ & $\sqrt{ }$ & $\sqrt{ }$ \\
\hline 47 & trans-Aconitate & $\sqrt{ }$ & $\sqrt{ }$ & $\sqrt{ }$ & $\sqrt{ }$ \\
\hline 48 & Trigonelline & $\sqrt{ }$ & $\sqrt{ }$ & $\sqrt{ }$ & $\sqrt{ }$ \\
\hline 49 & Tyrosine & - & - & - & $\sqrt{ }$ \\
\hline 50 & Valine & $\sqrt{ }$ & $\sqrt{ }$ & $\sqrt{ }$ & $\sqrt{ }$ \\
\hline
\end{tabular}




\begin{tabular}{|llllll|}
\hline & Compound Name & EC & OC & ES & OS \\
\hline 51 & $\beta$ alanine & $\sqrt{ }$ & $\sqrt{ }$ & $\sqrt{ }$ & $\sqrt{ }$ \\
\hline
\end{tabular}

Table 2

List of chemical shifts of unknown metabolites based on fold change analysis.

\begin{tabular}{|lllll|}
\hline \multirow{2}{*}{ Comparison } & \multicolumn{3}{l}{${ }^{1} \mathrm{H}$ chemical shift (ppm) } & \\
\cline { 2 - 4 } & Unknown 1 & Unknown 2 & Unknown 3 & Unknown 4 \\
\hline EC versus OC & 2.20 & 2.75 & 6.51 & 6.88 \\
\hline EC versus ES shoots & 2.56 & - & - & - \\
\hline OC versus OS shoots & 5.45 & - & -- & - \\
\hline
\end{tabular}

Table 3

List of unknown's chemical shift of significantly different metabolites based on heat map correlation.

\begin{tabular}{|lllll|}
\hline Comparison & \multicolumn{3}{l}{${ }^{1} \mathrm{H}$ chemical shift (ppm) } \\
\cline { 2 - 5 } & Unknown 1 & Unknown 2 & Unknown 3 & Unknown 4 \\
\hline EC versus OC & 2.20 & 4.45 & 6.51 & 6.88 \\
\hline EC versus ES shoots & 1.25 & 1.33 & 2.56 & 3.05 \\
\hline OC versus OS shoots & 4.30 & 4.75 & 5.45 & - \\
\hline
\end{tabular}

Figures 

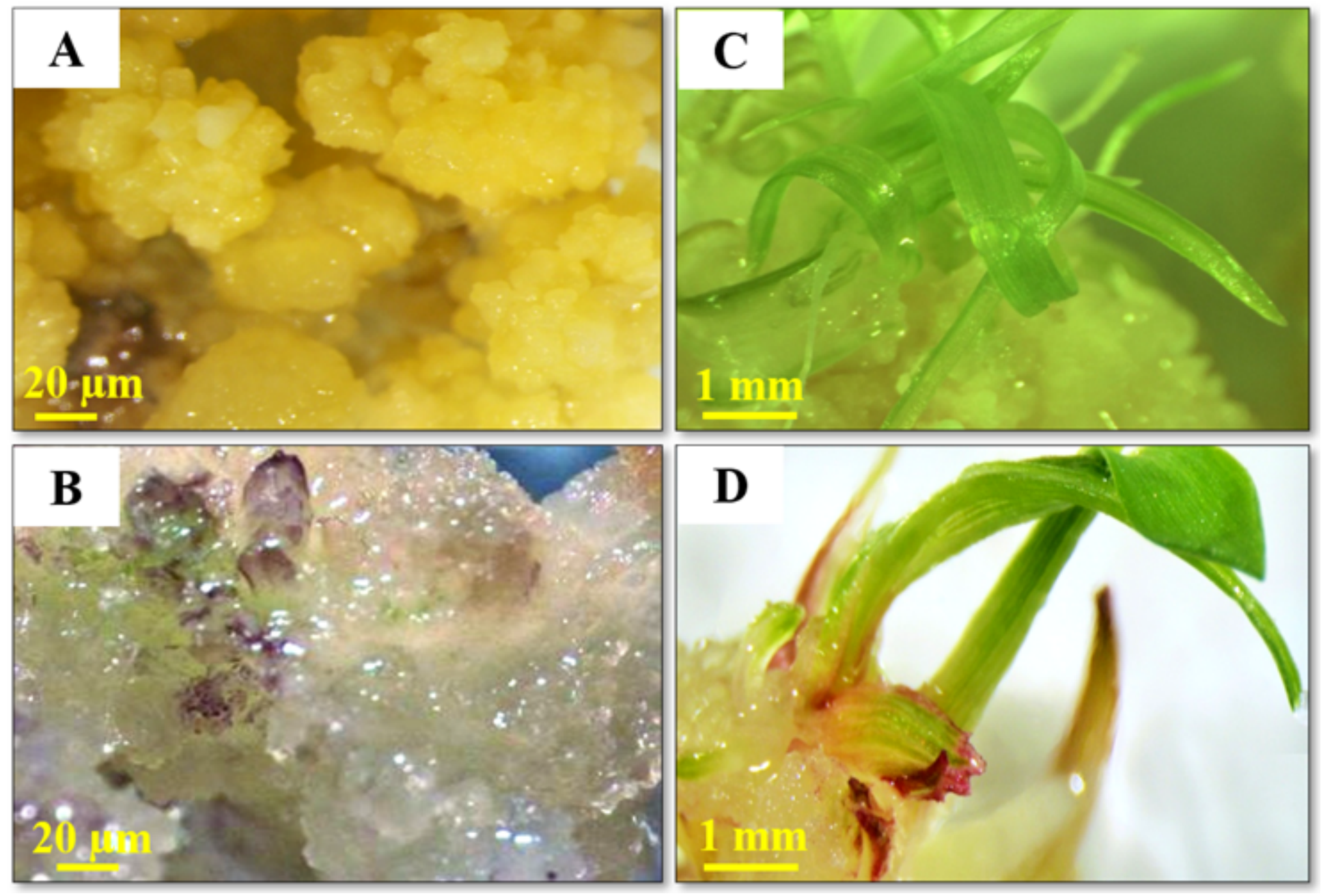

\section{Figure 1}

In vitro regeneration of C. schoenanthus subsp. proximus. A) Embryogenic calli; B) Organogenic calli; C) Embryogenic shoots; D) Organogenic shoots 

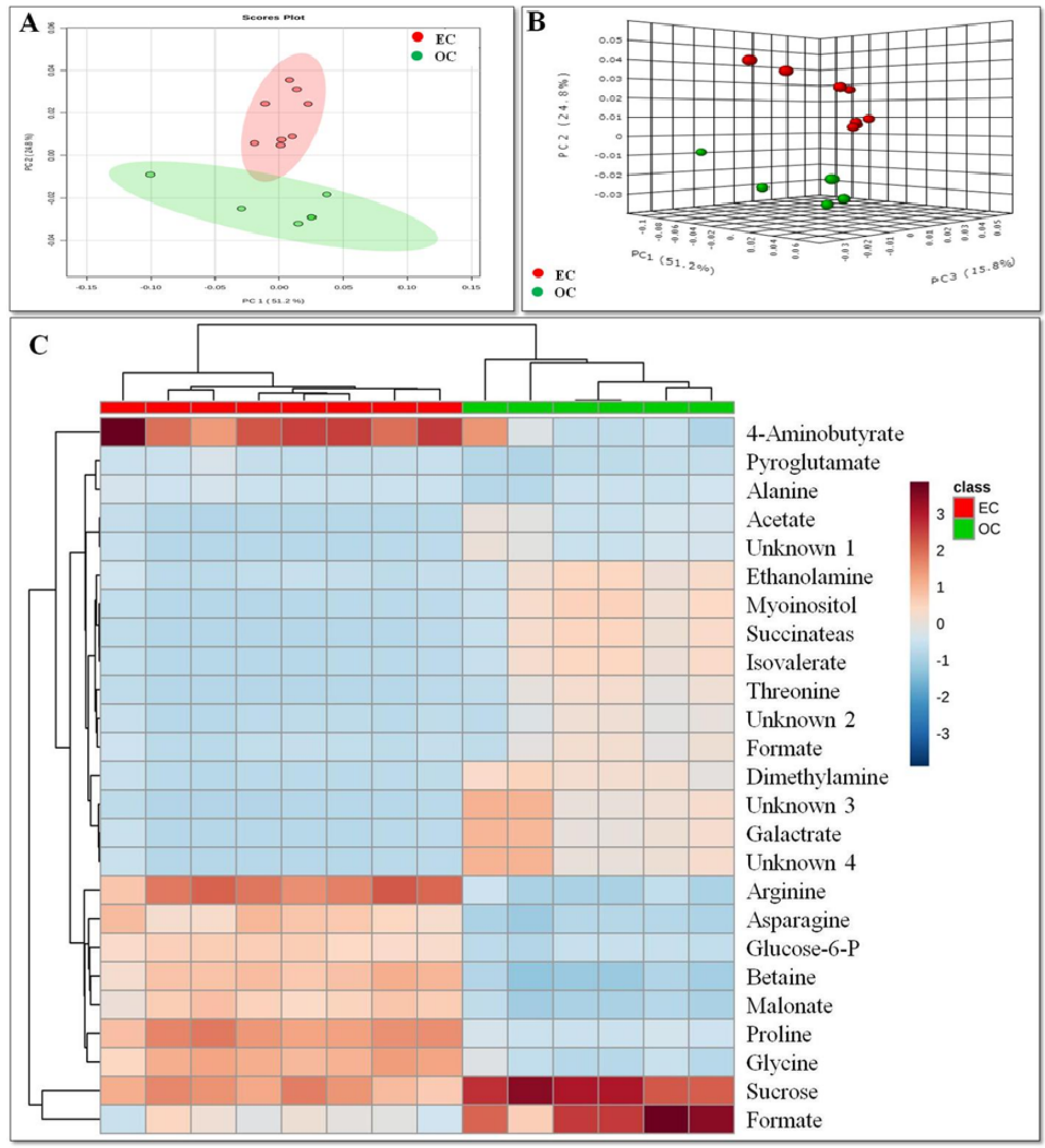

\section{Figure 2}

Metabolites variables associated with callus type $(E C=$ embryogenic calli and $\mathrm{OC}=$ organogenic calli). A \& B: Pair-wise PCA analysis. The ovals in the 2D score plot indicate $95 \%$ Hotellings confidence intervals. PC1 and PC2 explained the total of 76\% variance and PC3 explained $91.8 \%$ of total variance. C) Heat-map dendrogram showing a relative abundance of metabolites concentration in the polar extract of 
morphogenic calli. Colour scale is relative to the abundance of each metabolite. Each row represents a metabolite, and each column represents a sample of calli
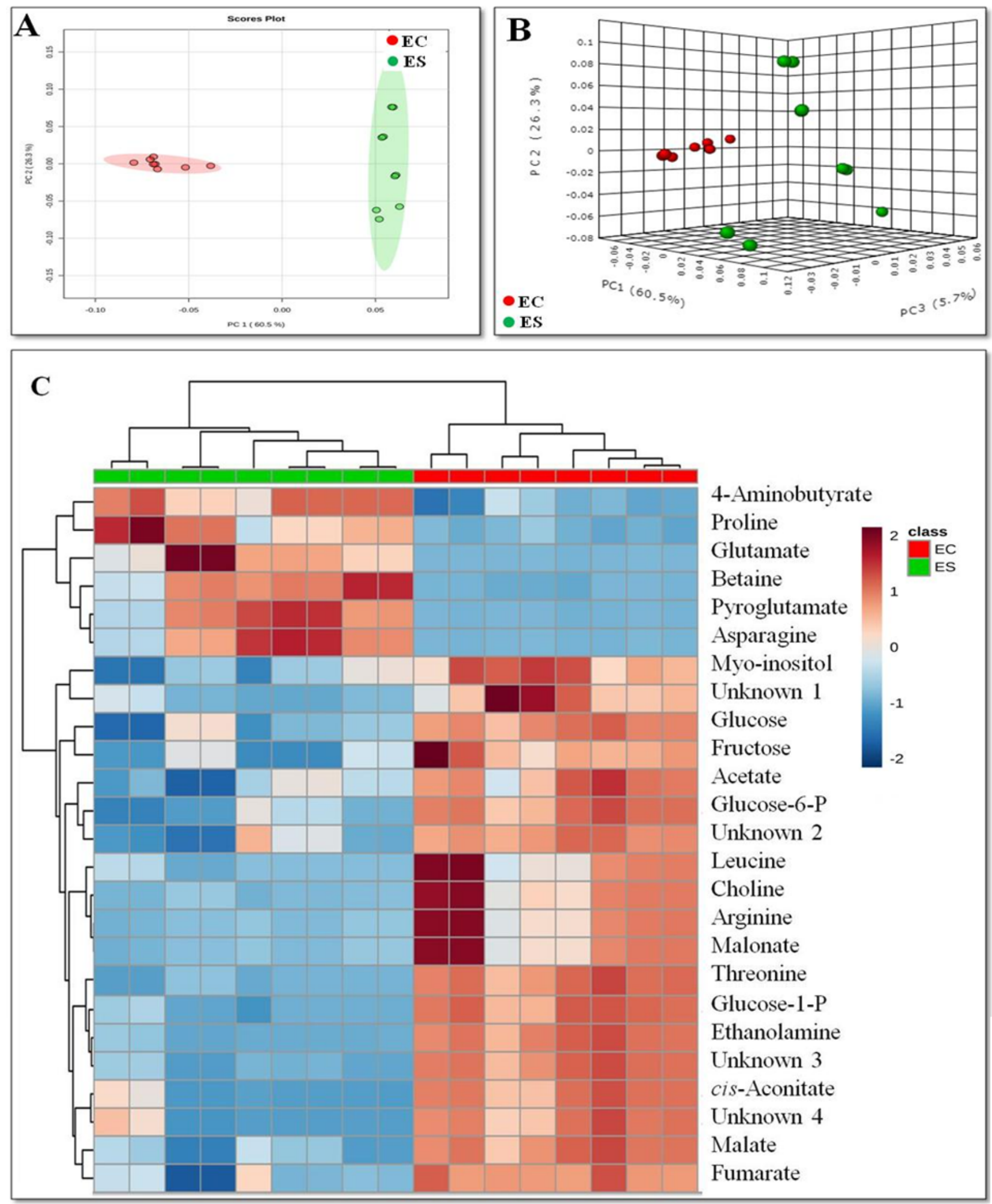

Figure 3

Metabolites variables associated with embryogenic calli and shoots $(\mathrm{EC}=$ embryogenic callus and $\mathrm{ES}=$ em-bryogenic shoots. A \& B: Pair-wise PCA analysis. The ovals in the 2D score plot indicate $95 \%$ Hotellings confidence intervals. PC1and PC2 explained the total of $86.8 \%$ variance and PC3 explained 
92.5\% of total variance. C) Heat-map dendrogram showing a relative abundance of metabolites concentration. Colour scale is relative to the abundance of each metabolite in the polar extract. Each row represents a metabolite, and each column represents a replicate
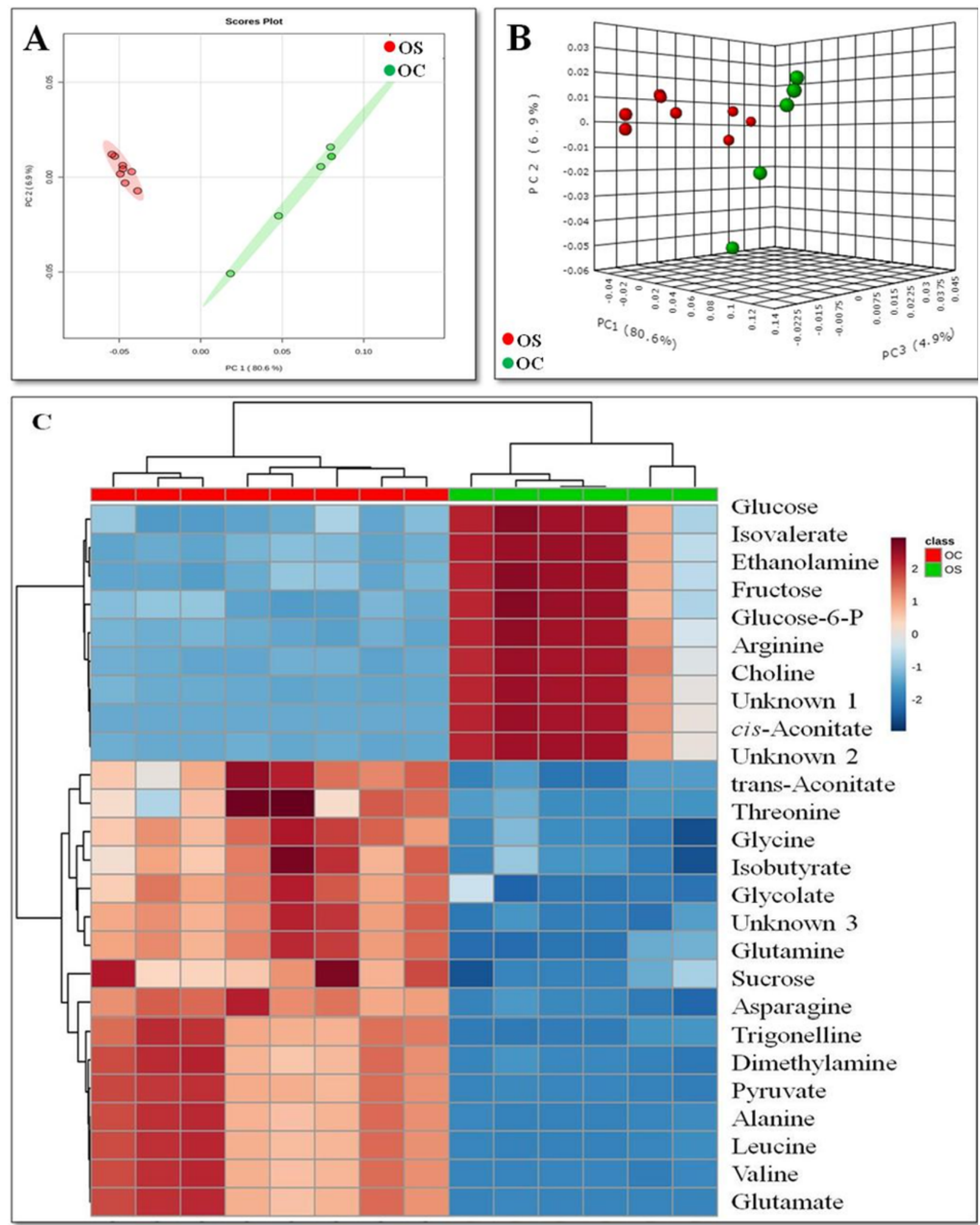

Figure 4

Metabolites variables associated with organogenic calli and shoots $(\mathrm{OC}=$ organogenic callus, $\mathrm{OS}=$ organogenic shoots). A \& B: Pair-wise PCA analysis. The ovals in the 2D scores plot indicate 95\% 
Hotellings confidence in-tervals. PC1 and PC2 explained the total of $87.5 \%$ variance and PC3 explained $92.4 \%$ of total variance. C) Heat-map dendrogram showing a relative abundance of metabolites concentration. Colour scale is relative to the abundance of each compound. Each row represents a metabolite, and each column represents a sample of calli and shoots

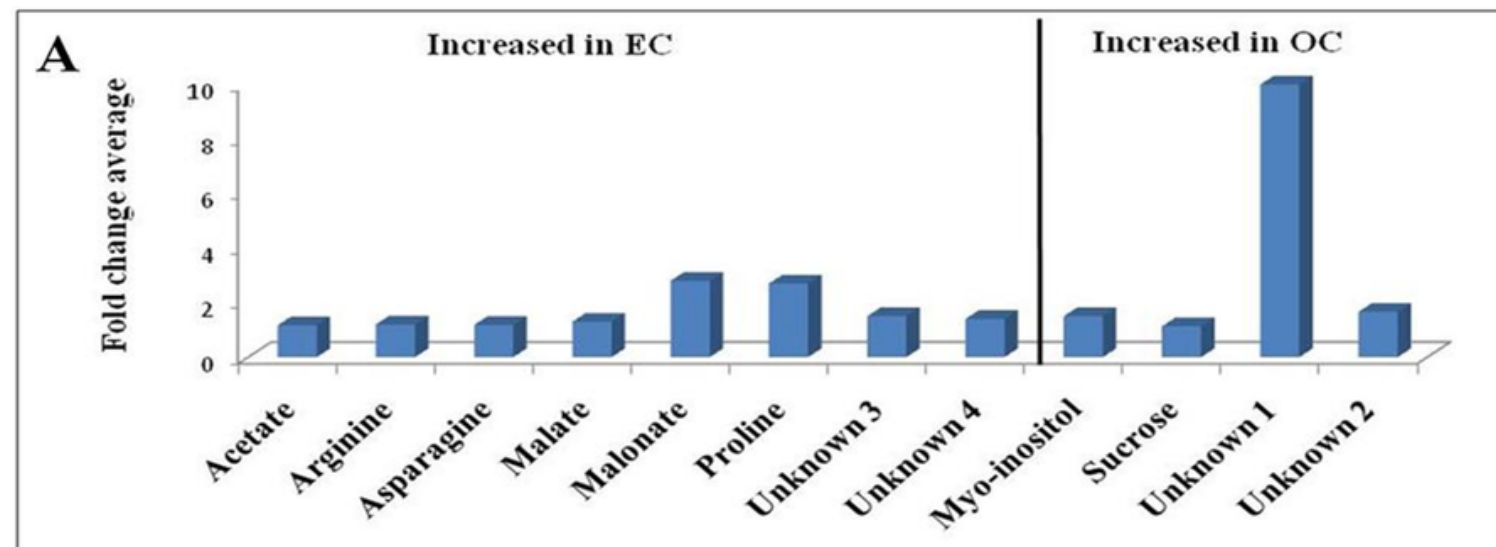

Significant metabolites

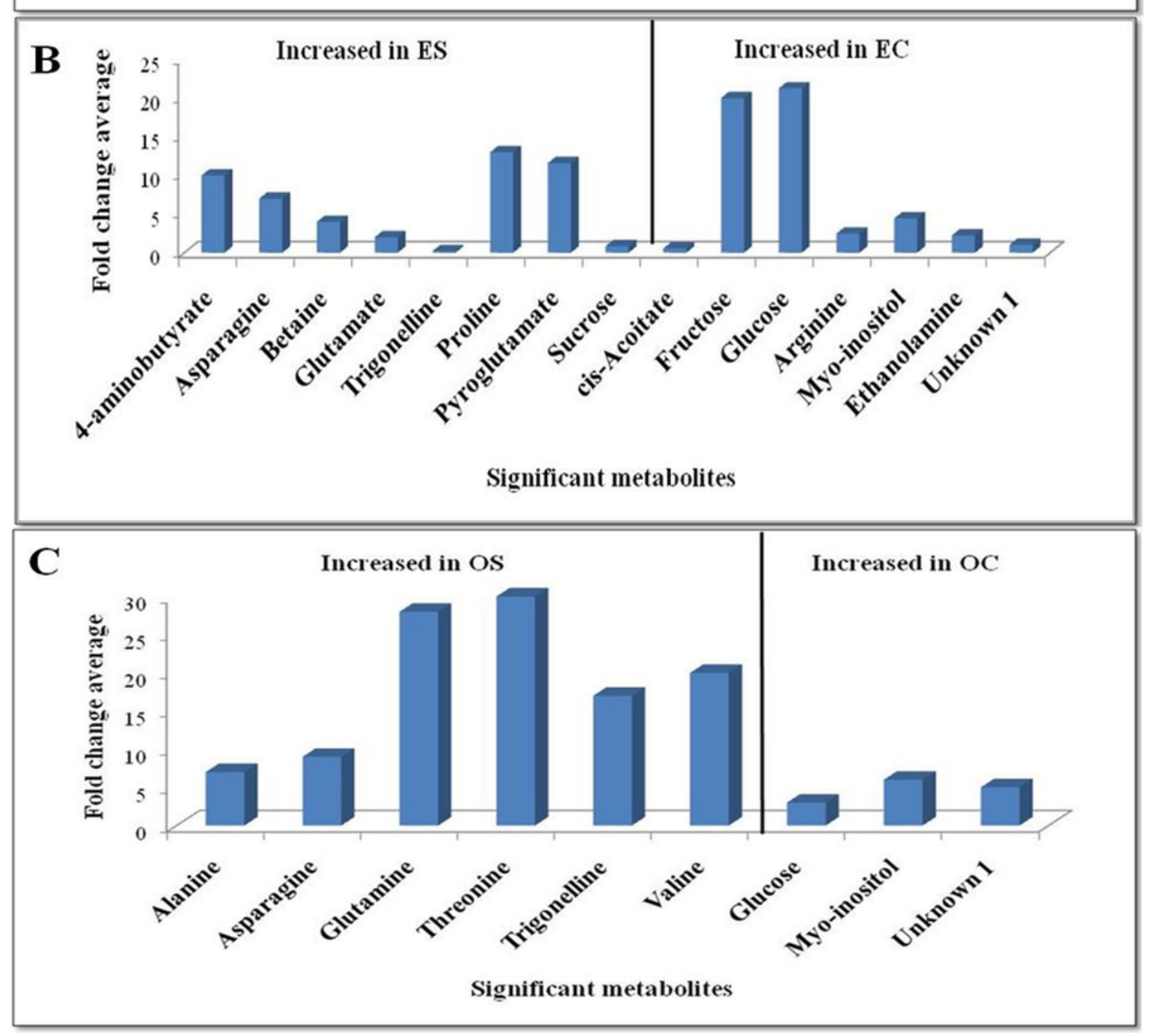

Figure 5 
Fold change analysis (fold change threshold $=1$ ) showing thesignificant change in metabolite concentrations between pairwise groups. A) Embryogenic calli= EC and organogenic calli=OC; B) Embryogenic shoots $=E S$ and embryogenic calli $=E C ; C$ ) Organogenic shoots $=O C$ and organogenic calli $=\mathrm{OC}$
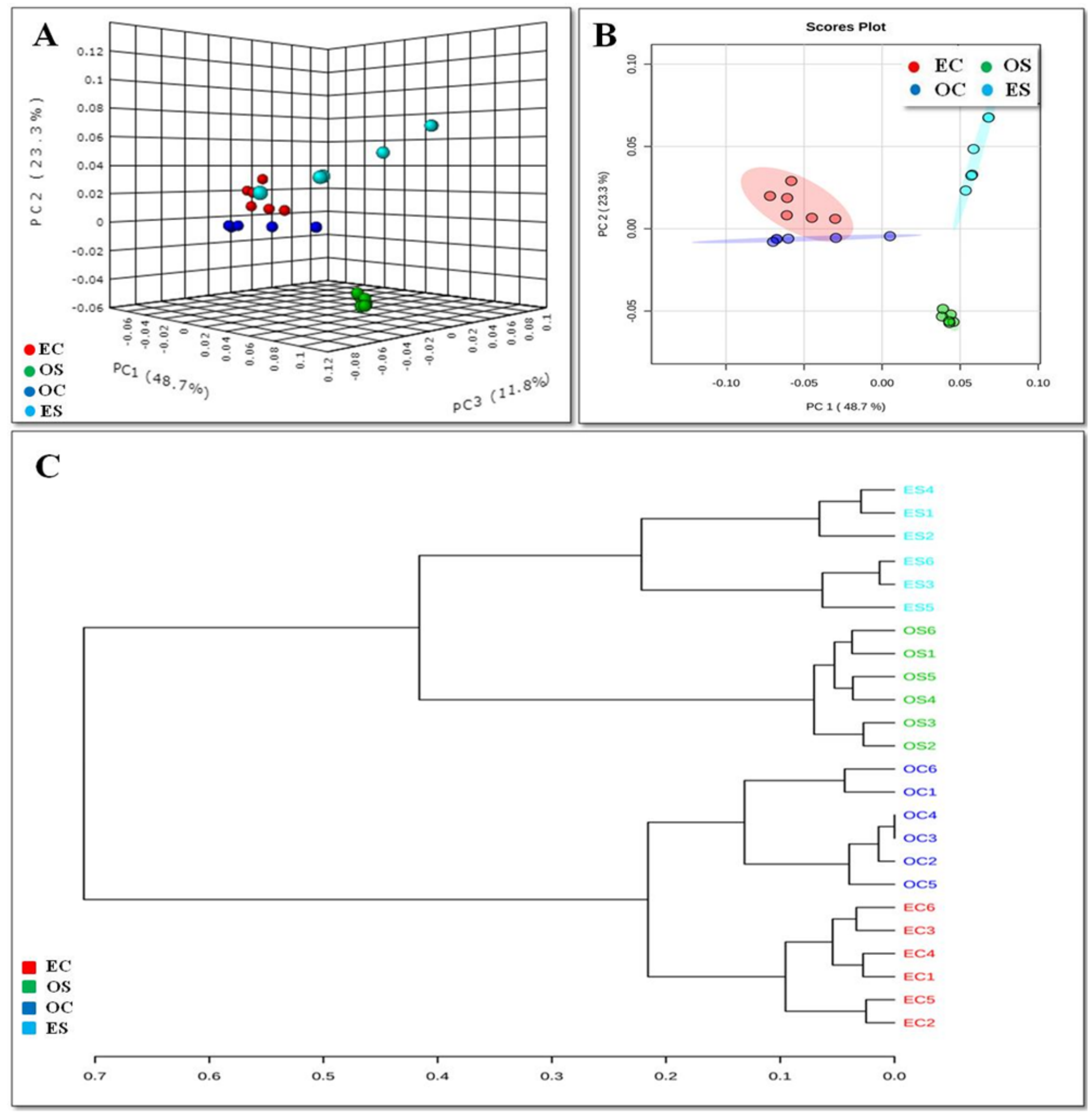

Figure 6 
Multivariate analysis, (A) 2D and (B) 3D score plots for embryogenic callus= EC; organogenic callus=OC; embryogenic shoots= ES shoots; organogenic shoots= OS. The ovals in the 2D scores plot indicate $95 \%$ Hotellings confidence intervals. PC1 and PC2 explained $72 \%$ of the model variance, while PC3 explained $83.8 \%$ of the total variance. (C) Hierarchical cluster analysis (HCA) dendrogram showing correlations between embryogenic and orga-nogenic calli and shoots based on metabolites variation.

\section{Supplementary Files}

This is a list of supplementary files associated with this preprint. Click to download.

- supplementarydata.docx 